\title{
The anti-allergic activity of Lactobacillus plantarum L67 and its application to yogurt
}

\author{
Sooyeon Song, ${ }^{*}$ Sei-Jung Lee, $†$ Dong-June Park, $\ddagger$ Sejong Oh, $\S^{1}$ and Kye-Taek Lim $\S^{1}$ \\ *Department of Food Science, Cornell University, 411 Tower Road, Ithaca, NY 14853 \\ †Department of Veterinary Physiology, College of Veterinary Medicine, Research Institute for Veterinary Science, \\ and BK21 PLUS Creative Veterinary Research Center, Seoul National University, Seoul 08826, South Korea \\ ¥Food Research Institute, 62 Anyangpangyo-ro, 1201 Beon-gil, Bundang-gu, Seongnam-si, Gyeonggi-do 13539, South Korea \\ §Division of Animal Science, Chonnam National University, 77 Yongbong-Ro, Buk-Gu, Gwang-Ju, 500-757, South Korea
}

\begin{abstract}
Recently, interest in the beneficial role of probiotics in the protection and management of allergic diseases caused by immune disorders has been increasing. This study investigated the inhibitory effect of Lactobacillus plantarum L67 on induced allergic inflammatory response in bisphenol A-treated rat basophilic leukemia 2H3 (RBL-2H3) cells and mouse splenocytes. We also evaluated the applicability of $L$. plantarum L67 as a yogurt starter culture. We measured the ability of Lactobacillus strains to induce the production of IL-12 and IFN- $\gamma$ in cultured splenocytes by ELISA. Bisphenol A $(50 \mu M)$-treated RBL-2H3 cells were cotreated with a glycoprotein $(18 \mathrm{kDa})$ isolated from L. plantarum $\mathrm{L} 67$ (5-100 $\mu \mathrm{g} / \mathrm{mL})$ for $30 \mathrm{~min}$. We measured the expression of mitogen-activated protein kinase (ERK and p38), AP-1 (c-Fos and c-Jun), T-bet, and GATA-binding protein 3 (GATA-3) using Western blotting to examine the differentiation of $\mathrm{T}$ helper cells. Furthermore, we evaluated the gene expression of IL-1 $\beta$, IL- 6 , and IL-10 using real-time quantitative PCR. Finally, we evaluated the applicability of L. plantarum L67 as a yogurt starter by measuring $\mathrm{pH}$, enumeration of bacteria, and sensory scores. Our results showed that L67 protein inhibited the phosphorylation of ERK and p38 mitogen-activated protein kinase through the transcriptional activation of AP-1 in bisphenol A-treated RBL-2H3 cells. During differentiation of $\mathrm{T}$ helper cells, the expression of transcription factor GATA-3 was significantly suppressed by L67 protein $(100 \mu \mathrm{g} / \mathrm{mL})$ treatment, whereas expression of transcription factor T-bet was increased. In addition, the L67 protein significantly attenuated the expression of $\mathrm{T}$ helper 2-linked cytokines IL-1 $\beta$, IL-6, and IL-10. These results indicate that $L$. plantarum L67, made available as yogurt starters and dietary sup-
\end{abstract}

Received August 1, 2016.

Accepted September 2, 2016.

${ }^{1}$ Corresponding authors: soh@jnu.ac.kr and ktlim@chonnam.ac.kr plements, has the potential to prevent allergy-related immune disorders.

Key words: allergy, bisphenol A, Lactobacillus plantarum L67, starter

\section{INTRODUCTION}

Recent studies have demonstrated that probiotics have beneficial effects for human health. Probiotics are live microorganisms that can improve the balance of beneficial intestinal microflora in the host organism (Sornplang and Piyadeatsoontorn, 2016). Lactobacillus plantarum, in particular, exhibits numerous beneficial effects as an anti-cancer agent, an anticoagulant, an antiviral, and immune modulator, an anti-inflammatory, an anti-diabetic agent, and an antioxidant; it also exhibits free radical scavenging activity (Andersson et al., 2010; Li et al., 2012; Giardina et al., 2014; Kassayová et al., 2014). In addition, some lactobacilli have been shown to inhibit type I allergic diseases by regulating the immune system (Segawa et al., 2008; Hong et al., 2014; Konieczna et al., 2015). These investigations have revealed that specific probiotic bacteria may be a promising tool for promoting potentially anti-allergic processes through immune regulation.

Glycoproteins isolated from some Lactobacillus strains have been known to have beneficial effects, such as controlling immature dendritic cells, regulating Tcell function, and inhibiting the adherence of pathogens in the gut (Rhee and Park, 2001; Johnson-Henry et al., 2007; Konstantinov et al., 2008; Song et al., 2015). The glycoprotein $(18 \mathrm{kDa})$ isolated from $L$. plantarum L67 is known to have anti-inflammatory and anti-allergy effects (Song et al., 2016a,b).

Bisphenol A (BPA) is an estrogenic, endocrinedisrupting chemical that has been used extensively in dentistry, food packaging, and lacquers for food cans and water pipes (Vandenberg et al., 2007). Additionally, BPA has been shown to affect the immune system in both humans and other animals. Recent studies have 
shown that BPA can interfere with the immune system via the production of cytokines and immunoglobulins in macrophages. Exposure to BPA can regulate the expression of T helper (Th) type 2 (Th2)-related cytokines, including IL-6 and IL-10, as well as increase the production of IL-4 and antigen-specific IgE (Yan et al., 2008; Lee and Lim, 2010; O'Brien et al., 2014). Several environmental chemicals, including BPA, are commonly used in everyday life, and these chemicals can affect human endocrine and immune systems (Chalubinski and Kowalski, 2006). Moreover, BPA can cause diseases such as atopic dermatitis, allergic rhinitis, and bronchial asthma (Bornehag et al., 2004; Jaakkola et al., 2004).

Allergic inflammation occurs via activation of Th2related cytokines to induce a Th1/Th2 imbalance. It has been reported that Th1 and Th2 cells are differentiated from $\mathrm{T}$ helper cell $\mathrm{Th} 0$ by specific transcription factors such as T-box expressed in T-cells (T-bet) and GATA-binding protein 3 (GATA-3). We know that T-bet is associated with the differentiation of Th1 cells and IFN- $\gamma$ secretion (Szabo et al., 2003), and that GATA-3 plays a pivotal role in Th2 cell differentiation and inhibits Th1 cell differentiation (Szabo et al., 2000; Zhu et al., 2006).

Recently, we identified a bacterial strain that induced the overexpression of IL-12 and IFN- $\gamma$ in mouse splenocytes. We isolated a glycoprotein $(18 \mathrm{kDa})$ from this strain. This glycoprotein inhibited allergy-related factors, including histamine and $\beta$-hexoaminidase (Song et al., 2016a).

In this study, we found that the glycoprotein (18 $\mathrm{kDa}$ ) isolated from L. plantarum L67 (L67 protein) inhibits allergy-related inflammatory mediators in BPAtreated rat basophilic leukemia 2H3 (RBL-2H3) cells and primary cultured splenocytes. First, we measured the levels of ERK, p38, and AP-1 by Western blotting. To study the differentiation of $\mathrm{T}$ helper cells, we also evaluated GATA-3 and T-bet expression by Western blotting. We evaluated the expression of IL-1 $\beta$, IL-6, and IL-10 cytokines by real-time quantitative PCR. Finally, we evaluated the applicability of L. plantarum L67 as a yogurt starter culture by measuring $\mathrm{pH}$, enumeration of bacteria, and sensory scores.

\section{MATERIALS AND METHODS}

\section{Chemicals and Reagents}

We obtained BPA, penicillin G, and streptomycin from Sigma-Aldrich (St. Louis, MO), and we purchased Dulbecco's modified Eagle medium and fetal bovine serum from Gibco BRL (Grand Island, NY). Other chemicals and reagents were of the highest analytical grade.

\section{Bacterial Strains and Culture}

The Lactobacillus strains used in this study were isolated from infant feces or kimchi. Lactobacillus strains were selected according to their colony characteristics, and they were tested for catalase activity and by Gram staining. These isolates were further screened for their acid and bile salt tolerance capacities according to the method by Park et al. (2002). To identify Lactobacillus strains, biochemical properties were first examined using an API 50 CHL kit (BioMerieux, Marcy l'Étoile, France) and 16S rDNA sequencing data as described by Song et al. (2014). Eighteen strains were identified and evaluated in this study (Table 1). Lactobacillus strains were grown in de Man, Rogosa, and Sharpe (MRS) broth (Difco, Detroit, MI) at $37^{\circ} \mathrm{C}$ for $18 \mathrm{~h}$. The bacterial cells were separated by centrifugation at $3,000 \times g$ for $15 \mathrm{~min}$ at room temperature, and the precipitated cells were washed twice with sterile saline (0.85\% sodium chloride). Skim milk (10\%) was added to the sediments, and the suspension was stored at $-80^{\circ} \mathrm{C}$ until use.

\section{IL-12 and IFN- $y$ Production by Mouse Splenocytes}

We evaluated the ability of Lactobacillus strains to induce the production of IL-12 and IFN- $\gamma$ using cultured splenocytes obtained from BALB/c mice. Splenocytes cultured in RPMI 1640 medium containing 10\% fetal bovine serum, $100 \mathrm{U} / \mathrm{mL}$ penicillin, and $100 \mu \mathrm{g} /$ $\mathrm{mL}$ streptomycin, were seeded at $2.5 \times 10^{6}$ cells $/ \mathrm{mL}$ on a 96-well culture plate. Spleen cells were cultured with or without $2.5 \times 10^{6} \mathrm{cfu} / \mathrm{mL}$ lactobacilli at $37^{\circ} \mathrm{C}$ and $5 \% \mathrm{CO}_{2}$. Supernatants were collected on d 3 to measure IL-12 and IFN- $\gamma$ production using ELISA. This study was carried out in strict accordance with the recommendations of the Guide for the Care and Use of Laboratory Animals of the National Institutes of Health (Bethesda, MD). The protocol was approved by the committee on the Ethics of Animal Experiments of Chonnam National University (permit number CNU IACUC-YB-2012-40). All surgeries were performed under sodium pentobarbital anesthesia, and all efforts were made to minimize suffering of animals.

\section{Preparation of Glycoprotein Isolated from $L$. plantarum $L 67$}

For preparation of glycoprotein, $10 \mathrm{~mL}$ of L. plantarum L67 culture was obtained after $18 \mathrm{~h}$ of incubation at 
Table 1. Genotypic methods applied for identification of lactobacilli

\begin{tabular}{llcl}
\hline Strain ID & $\begin{array}{l}\text { Closest relative } \\
\text { (by 16S rDNA gene sequencing) }\end{array}$ & Identity (\%) & $\begin{array}{l}\text { Gene bank } \\
\text { accession no. }\end{array}$ \\
\hline 1 & Lactobacillus curvatus & 99 & KJ914899.1 \\
2 & Lactobacillus curvatus & 99 & KC787548.1 \\
3 & Lactobacillus curvatus & 99 & AB600197.1 \\
4 & Lactobacillus sakei & 99 & KC416998.1 \\
5 & Lactobacillus brevis & 99 & JX966418.1 \\
6 & Lactobacillus brevis & 98 & FJ227309.1 \\
7 & Lactobacillus brevis & 98 & FJ532364.1 \\
8 & Lactobacillus brevis & 99 & HM162416.1 \\
9 & Lactobacillus brevis & 99 & AB548886.1 \\
10 & Lactobacillus farciminis & 99 & FJ532365.1 \\
11 & Lactobacillus sakei & 99 & EU626014.1 \\
12 & Lactobacillus sakei & 99 & JQ517277.1 \\
13 & Lactobacillus fermentum & 99 & EU636427.1 \\
14 & Lactobacillus acidophilus & 99 & EU626017.1 \\
15 & Lactobacillus acidophilus & 100 & KR336551 \\
L67 & Lactobacillus plantarum & 99 & KM036427.1 \\
17 & Lactobacillus fermentum & 99 & EU626013.1 \\
18 & Lactobacillus plantarum & & \\
\hline
\end{tabular}

$37^{\circ} \mathrm{C}$. Pellets were collected by centrifugation at 12,000 $\times g$ at $4^{\circ} \mathrm{C}$, and washed 3 times with sterile deionized water. The washed cells were resuspended in $10 \mathrm{~g} / \mathrm{L}$ of SDS solution and boiled for $10 \mathrm{~min}$. The supernatants were harvested after centrifugation at $12,000 \times g$ at $4^{\circ} \mathrm{C}$ for $15 \mathrm{~min}$ and dialyzed against distilled water at $4^{\circ} \mathrm{C}$. Supernatants were dried using a freeze-dryer and stored at $-70^{\circ} \mathrm{C}$ (Song et al., 2016a). Protein concentrations were measured using the Bradford assay (Bradford, 1976).

\section{Cell Culture}

The RBL-2H3 cells were provided by the Korea Cell Line Bank (Seoul, Korea). The cells were incubated in Dulbecco's modified Eagle medium supplemented with fetal bovine serum $(10 \%)$, penicillin $(100 \mathrm{U} / \mathrm{mL})$, and streptomycin $(100 \mu \mathrm{g} / \mathrm{mL})$ at $37^{\circ} \mathrm{C}$ and $5 \% \mathrm{CO}_{2}$. The medium was changed twice a week. The cells $(2.3 \times$ $10^{6}$ cells $/ \mathrm{mL}$ ) were divided into 6 -well plates. Splenocytes were collected from BALB/c mice using aseptic conditions in Hanks' balanced salt solution. Spleens were crushed by passage through a $40-\mu \mathrm{m}$ cell strainer (Falcon, Corning Inc., Corning, NY). The supernatant of homogeneous cells was precipitated by adding ammonium chloride $(0.8 \% \mathrm{wt} / \mathrm{vol})$. After centrifugation, the cells were washed with PBS and resuspended in RPMI 1640 medium supplemented with fetal bovine serum $(10 \%)$, penicillin $(100 \mathrm{U} / \mathrm{mL})$, and streptomycin $(100 \mathrm{mg} / \mathrm{mL})$ at $37^{\circ} \mathrm{C}$ in $5 \% \mathrm{CO}_{2}$. Then, cells $(1 \times$ $10^{6}$ cells $/ \mathrm{mL}$ ) were divided into 6 -well or 96 -well flatbottomed plates. They were then cotreated with $50 \mu M$ BPA and L67 protein $(5-100 \mu \mathrm{g} / \mathrm{mL})$ for $30 \mathrm{~min}$.

\section{Preparation of Cell Extracts for Western Blotting}

Cells were stimulated with BPA $(50 \mu M)$ or cotreated with L67 protein $(5-100 \mu \mathrm{g} / \mathrm{mL})$ for $30 \mathrm{~min}$. Cells were then rinsed with PBS after removing the medium. Protein was isolated according to the method of $\mathrm{Oh}$ and Lim (2008). Protein concentration was measured using the Lowry method (Lowry et al., 1951), and protein samples were stored at $-70^{\circ} \mathrm{C}$.

\section{Western Blot Analysis}

Proteins were analyzed by $10 \%$ polyacrylamide mini-gel electrophoresis at $100 \mathrm{~V}$ for $2 \mathrm{~h}$ at room temperature using a Mini-Protean II electrophoresis cell (Bio-Rad, Hercules, CA). After protein transfer onto nitrocellulose membranes (Millipore, Bedford, MA), the membranes were incubated overnight at $4^{\circ} \mathrm{C}$ with rabbit polyclonal antibodies [1:3,000, T-bet, GATA-3, mitogen-activated protein kinase (MAPK), AP-1, and $\alpha$-tubulin] in Tris-buffered saline Tween 20 (TBS-T) solution. After 3 washes with TBS-T, the membranes were incubated with horseradish peroxidase-conjugated goat anti-rabbit IgG (1:10,000; Cell Signaling, Danvers, MA) in TBS-T solution for $1 \mathrm{~h} 30 \mathrm{~min}$ at room temperature. Protein bands were visualized by chemiluminescence (ELPIS Biotechnology, Taejeon, Korea). Band intensities were measured using Scion imaging software (Scion Image Beta 4.02, MD).

\section{RNA Isolation and Real-Time Quantitative PCR}

Total RNA was isolated using an RNeasy Mini Kit (Qiagen, Valencia, CA), according to the manufac- 
Table 2. Oligonucleotides used for real-time PCR

\begin{tabular}{ll}
\hline Gene & Sequence of PCR primers $\left(5^{\prime}\right.$ to $\left.3^{\prime}\right)$ \\
\hline IL-1 $\beta$ & Forward: TTGACGGACCCCAAAAGATG \\
& Reverse: AGAAGGTGCTCATGTCCTCA \\
IL-6 & Forward: GTTCTCTGGGAAATCGTGGA \\
& Reverse: TGTACTCCAGGTAGCTATGG \\
IL-10 & Forward: CTGGACAACATACTGCTAACCGAC \\
& Reverse: ATTCATTCATGGCCTTGTAGACACC \\
GAPDH & Forward: CAAAAGGGTCATCATCTCTG \\
& Reverse: CCTGCTTCACCACCTTCTTG \\
\hline
\end{tabular}

turer's instructions (www.qiagen.com/goto/microRNAprotocols). We prepared cDNA from $1 \mu \mathrm{L}$ of total RNA $(1 \mu \mathrm{g} / 20 \mu \mathrm{L})$, using the Maxime RT Premix Oligo (dT) real-time quantitative PCR kit (Intron, Seongnam, Korea). The primers used are shown in Table 2. The expression levels of the respective genes were measured by real-time PCR using 2X Prime Q Master Mix (Kapa Biosystems, Boston, MA) and analyzed using a CFX96TM Real-Time system (Bio-Rad). Amplifications were conducted using 50 cycles for IL-1 $\beta$, IL-6, IL10 , and GAPDH $\left(30 \mathrm{~s}\right.$ at $95^{\circ} \mathrm{C}, 30 \mathrm{~s}$ at $56^{\circ} \mathrm{C}$, and $60 \mathrm{~s}$ at $72^{\circ} \mathrm{C}$; Table 2$)$. The sample $\Delta$ cycle threshold $(\mathrm{S} \Delta \mathrm{Ct}$ ) values were calculated as the differences between the Ct values for IL-1 $\beta$, IL-6, or IL-10, and the values for GAPDH (reference) in cells treated with BPA alone or cotreated with BPA and L67 protein. The relative gene expression levels between the treatment group and the control were determined using the formula: $2-(\mathrm{S} \Delta \mathrm{Ct}$ - C $\Delta \mathrm{Ct}$ ) (Livak and Schmittgen, 2001).

\section{Yogurt Manufacturing}

Yogurt was prepared by heating milk (SNF 11\%; raw milk with skim milk powder; Seoul Dairies, Seoul, Korea) to $95^{\circ} \mathrm{C}$ for $20 \mathrm{~min}$, and then cooling to $40^{\circ} \mathrm{C}$. Starter cultures were inoculated aseptically. Streptococcus thermophilus and Bifidobacterium species were grown in M17 broth (Difco, Detroit, MI) and in BL broth (Teraguchi et al., 1978), respectively. Lactobacillus acidophilus and L. plantarum L67 strains were grown in MRS broth (Difco). All strains were stored at $-80^{\circ} \mathrm{C}$ in reconstituted skim milk $(10 \%$ wt/vol $)$ yeast extract $(0.5 \% \mathrm{wt} / \mathrm{vol})$ medium and were cultured 3 times before use. The tested starters are indicated in Table 3. The $\mathrm{pH}$ value during fermentation was measured with a pH meter (FEP20; Mettler Toledo; Greifensee, Switzerland).

\section{Enumeration of Bacteria}

We enumerated L. acidophilus and L. plantarum L67 using MRS-maltose agar (Dave and Shah, 1996) and incubation $37^{\circ} \mathrm{C}$ for $48 \mathrm{~h}$; S. thermophilus using M17 agar at $43^{\circ} \mathrm{C}$ for $24 \mathrm{~h}$; and $B$. longum according to the method by Teraguchi et al. (1978) using BL-NPNL (nalidixic acid, paromomycin sulfate, neomycin sulfate, and lithium chloride) agar and incubated anaerobically (Bugbox; Ruskinn Technology, Bridgend, UK) at $37^{\circ} \mathrm{C}$ for $48 \mathrm{~h}$.

\section{Sensory Evaluations}

Samples were assessed organoleptically by 6 panelists. Properties were evaluated using sensory rating scales for flavor $(1-9$ points, no criticism $=9)$ and for texture and preference $(1-5$ points; no criticism $=5)$.

\section{Statistical Analysis}

All data are expressed as means with standard errors (SE). The data were processed with SAS software using ANOVA tests and the GLM procedure (SAS version 9.1; SAS Institute Inc., Cary, NC). We analyzed different groups using Duncan's multiple range test $(P$-value $<0.05)$.

\section{RESULTS}

\section{Detection of Lactobacilli Strains that Induced Significant IL-12 and IFN- $y$ Secretion from Splenocytes}

We measured the ability of 18 Lactobacillus strains to improve the Th1/Th2 balance in splenocytes. The secretion of Th1-related cytokines IL-12 and IFN- $\gamma$

Table 3. Composition of yogurt starter cultures

\begin{tabular}{lll}
\hline Culture & Composition of cultures & Source \\
\hline Starter A & Lactobacillus acidophilus La5 $\left(\sim 10^{6}\right)$, Bifidobacterium animalis ssp. & Chr. Hansen A/S, Hørsholm, Denmark \\
(control) & lactis Bb12 $\left(\sim 10^{6}\right)$, and Streptococcus thermophilus $\left(\sim 10^{7}\right)$ & Danisco USA Inc., New Century, KS \\
Starter B & Lactobacillus acidophilus NCFM $\left(\sim 10^{6}\right)$, Bifidobacterium longum $\left(\sim 10^{6}\right)$, and & \\
(control) & Streptococcus thermophilus $\left(\sim 10^{7}\right)$ & Culture Systems Inc., Mishawaka, IN \\
Starter C & Lactobacillus plantarum $\mathrm{L} 67\left(\sim 10^{6}\right)$, Bifidobacterium longum $\left(\sim 10^{6}\right)$, and & \\
\hline
\end{tabular}

\footnotetext{
${ }^{1}$ Numbers in parentheses indicate inoculum levels in milk $(\mathrm{cfu} / \mathrm{mL})$.
} 
Table 4. Production of IL-12 and IFN- $\gamma$ from mouse splenocytes induced by various strains of lactobacilli ${ }^{1}$

\begin{tabular}{lcc}
\hline Strain ID & IL-12 $(\mathrm{pg} / \mathrm{mL})$ & IFN- $\gamma(\mathrm{pg} / \mathrm{mL})$ \\
\hline Control & $0 \pm 0.12$ & $200 \pm 7.8$ \\
1 & $35.0 \pm 1.2$ & $1,900 \pm 75.2$ \\
2 & $38.4 \pm 1.1$ & $1,300 \pm 65.2$ \\
3 & $35.4 \pm 0.3$ & $2,050 \pm 10.3$ \\
4 & $25.6 \pm 0.2$ & $2,000 \pm 10.2$ \\
5 & $55.8 \pm 1.7$ & $1,000 \pm 8.7$ \\
6 & $17.3 \pm 0.4$ & $800 \pm 10.5$ \\
7 & $15.2 \pm 0.5$ & $1,310 \pm 54.3$ \\
8 & $10.9 \pm 0.3$ & $400 \pm 5.6$ \\
9 & $11.6 \pm 0.2$ & $408 \pm 7.8$ \\
10 & $64.3 \pm 0.6$ & $1,200 \pm 21.3$ \\
11 & $48.0 \pm 2.3$ & $550 \pm 6.4$ \\
12 & $68.9 \pm 8.7$ & $1,400 \pm 12.3$ \\
13 & $18.1 \pm 0.4$ & $1,950 \pm 15.3$ \\
14 & $13.3 \pm 0.3$ & $200 \pm 4.3$ \\
15 & $36.0 \pm 0.3$ & $300 \pm 3.2$ \\
L67 & $68.7 \pm 4.3$ & $1,800 \pm 43.2$ \\
17 & $16.2 \pm 0.4$ & $210 \pm 5.6$ \\
18 & $14.3 \pm 0.3$ & $1,850 \pm 20.2$ \\
\hline
\end{tabular}

${ }^{1}$ Splenocytes were isolated from BALB/c mice and cultured in RPMI 1640 medium containing $10 \%$ fetal bovine serum, $100 \mathrm{U} / \mathrm{mL}$ penicillin, and $100 \mu \mathrm{g} / \mathrm{mL}$ streptomycin at a density of $2.5 \times 10^{6}$ cells $/ \mathrm{mL}$ in a 96-well culture plate. Cells were cultured with or without $2.5 \times$ $10^{6} \mathrm{cfu} / \mathrm{mL}$ lactobacilli at $37^{\circ} \mathrm{C}$ and $5 \% \mathrm{CO}_{2}$. Supernatants were collected on d 3 to measure cytokine (IL-12, IFN- $\gamma$ ) production, and the concentrations of IL-12 and IFN- $\gamma$ in supernatants were determined by ELISA. from splenocytes was measured by ELISA. As shown in Table 4, the ability of splenocytes to induce IL-12 and IFN- $\gamma$ production depended on the Lactobacillus strain. Of the 18 investigated strains, we selected L. plantarum L67, which induced secretion of high levels of both IL12 and IFN- $\gamma$ in mouse splenocytes (Table 4).

\section{Effect of L67 Protein on Expression of p38 MAPK and ERK in BPA-Treated RBL-2H3 Cells}

To determine whether the L67 protein could suppress phosphorylation of p38 in BPA-treated RBL-2H3 cells, we analyzed p38 phosphorylation by Western blotting. Phosphorylation of p38 was increased 4.5-fold in BPA-treated RBL-2H3 cells compared with the control. However, the increased phosphorylation was reduced with L67 protein treatment to 3.67-, 3.62-, 3.43-, and 0.87 -fold relative to control $(5,20,50$, and $100 \mu \mathrm{g} /$ $\mathrm{mL}$, respectively; Figure 1). In addition, ERK activity was increased by treatment with BPA for 30 min, and this increased activity was reduced in a dose-dependent manner with L67 protein treatment.
(A)

$\begin{array}{lllllll}- & + & + & + & + & + & \text { BPA }(50 \mu M) \\ \text { Con } & 0 & 5 & 20 & 50 & 100 & \text { L67 protein }(\mu \mathrm{g} / \mathrm{mL})\end{array}$

(C)

$\begin{array}{ccccccl}- & + & + & + & + & + & \text { BPA }(50 \mu M) \\ \text { Con } & 0 & 5 & 20 & 50 & 100 & \text { L67 protein }(\mu \mathrm{g} / \mathrm{mL})\end{array}$

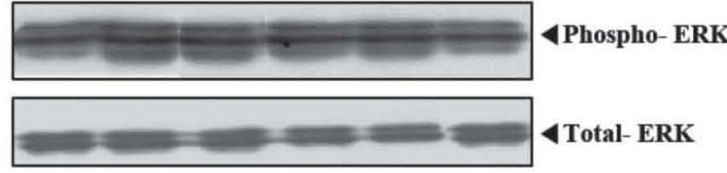

(B)

-P-ERK

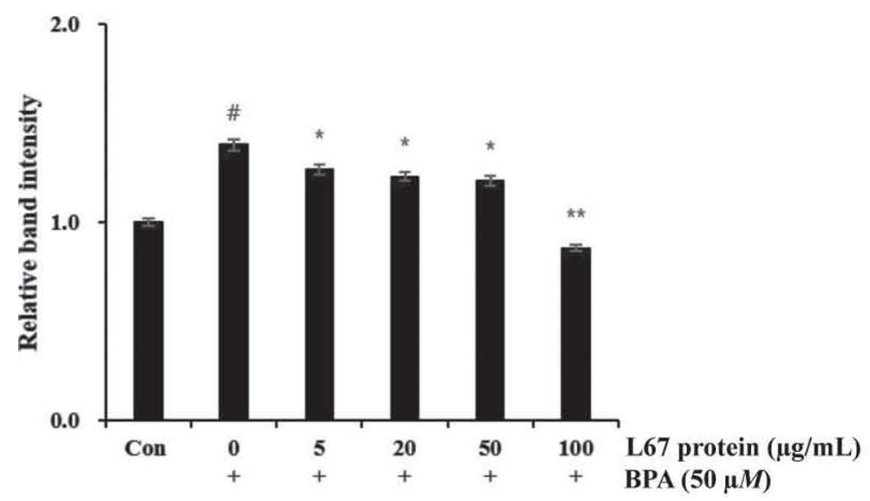

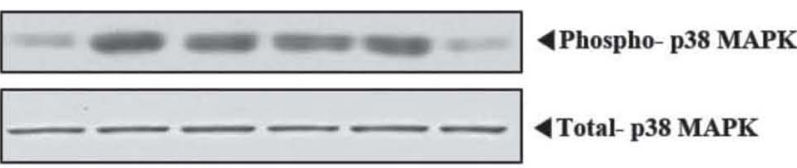

(D)

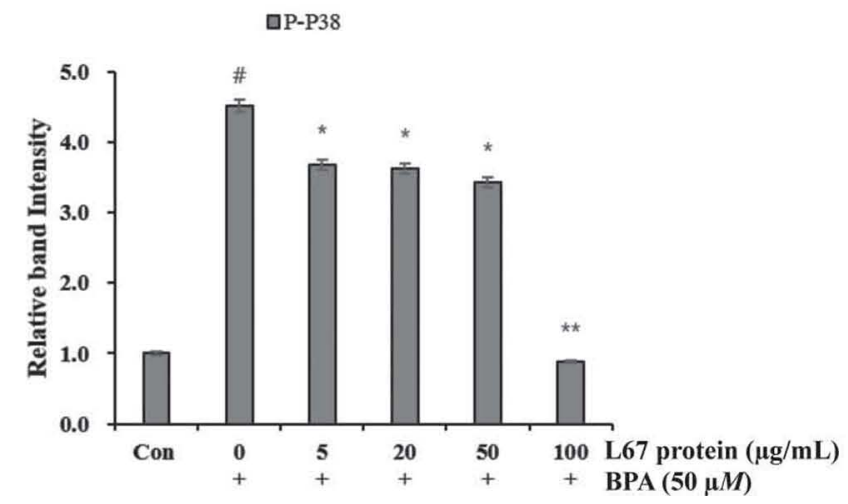

Figure 1. Inhibitory effect of Lactobacillus plantarum L67 protein on ERK (Western blot in A; relative band intensity in B) and p38 mitogenactivated protein kinase (MAPK; Western blot in C; relative band intensity in D) phosphorylation in bisphenol A (BPA)-treated RBL2H3 cells. Cells were treated with BPA $(50 \mu M)$ for $30 \mathrm{~min}$ in the absence or presence of L67 protein $(5,20,50$, and $100 \mu \mathrm{g} / \mathrm{mL})$. The relative intensities of the bands were analyzed using Scion imaging software (Scion Image Beta 4.02; Scion, Frederick, MD). All data are mean \pm SE from triplicates. \#Significant difference between treatments and controls $(P<0.05)$. *Significant difference between BPA and L67 protein treatments in the presence of BPA $(P<0.05)$. ${ }^{* *}$ Significant difference between BPA and L67 protein treatments in the presence of BPA $(P<0.01)$. Con $=$ control. 
(A)

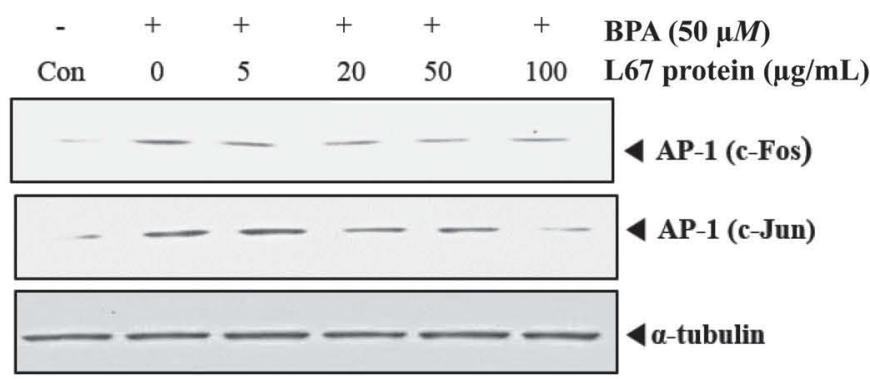

(B)

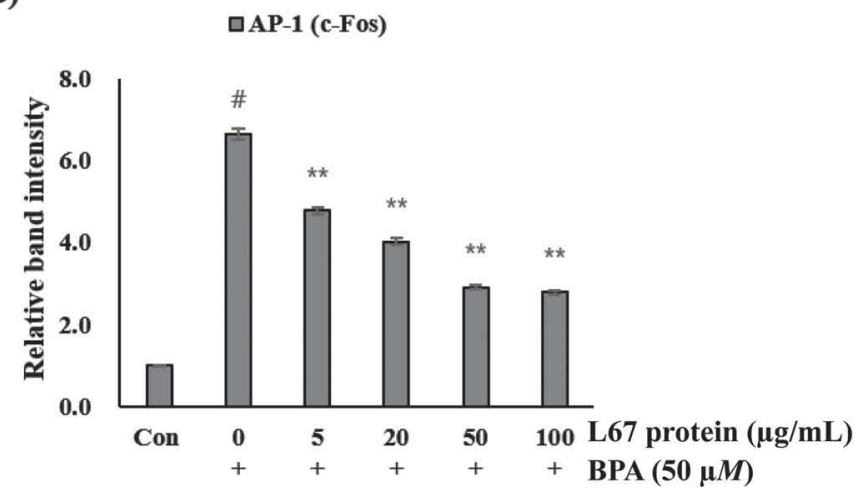

(C)

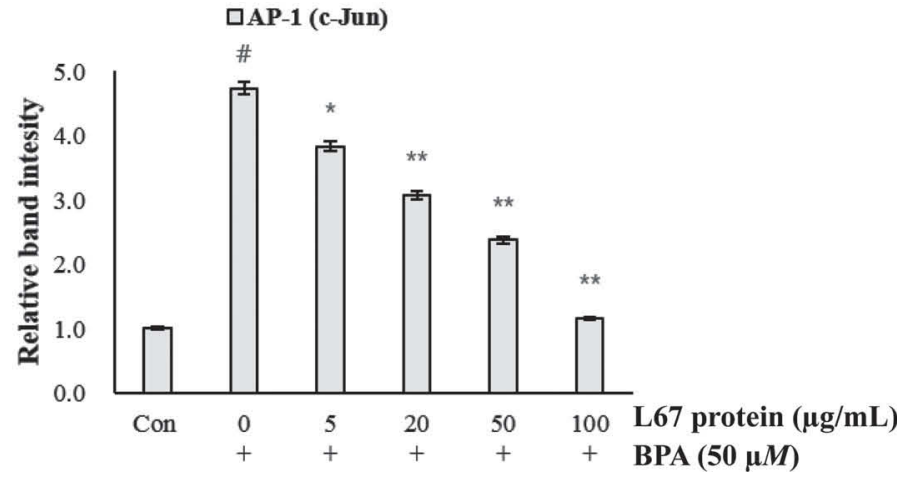

Figure 2. Inhibitory effect of Lactobacillus plantarum L67 protein on AP-1 (c-Fos and c-Jun) expression in bisphenol A (BPA)-treated RBL2H3 cells (Western blot in panel A; relative band intensities of c-Fos and c-Jun in panels B and C). Cells were treated with BPA (50 $\mu M$ ) for $30 \mathrm{~min}$ in the absence or presence of $\mathrm{L} 67$ protein $(5,20,50$, and $100 \mu \mathrm{g} / \mathrm{mL})$. The relative intensities of the bands were analyzed using Scion imaging software (Scion Image Beta 4.02; Scion, Frederick, MD). $\alpha$-Tubulin was used as an internal control. All data are mean \pm SE from triplicates. \#Significant difference between treatments and controls $(P<0.05)$; ***significant difference between BPA and L67 protein treatments in the presence of $\mathrm{BPA}\left({ }^{*} P<0.05 ;{ }^{* *} P<0.01\right)$. Con $=$ control.

\section{Effect of L67 Protein on Activity of AP-1 in BPA-Treated RBL-2H3 Cells}

As shown in Figure 2, phosphorylation of AP-1 (cFos) and AP-1 (c-Jun) increased by $6.65-$ and $4.73-$ fold, respectively, with BPA treatment $(50 \mu M)$ for 30 min. The increased phosphorylation of AP-1 (c-Fos) was diminished to 4.77-, 4.02-, 2.91-, and 2.79-fold in the presence of L67 protein $(5,20,50$ and $100 \mu \mathrm{g} / \mathrm{mL}$, respectively). The increased phosphorylation of AP-1 (c- Jun) was inhibited to 3.83-, 3.08-, 2.38-, and 1.17fold in the presence of L67 protein $(5,20,50$, and 100 $\mu \mathrm{g} / \mathrm{mL}$, respectively).

\section{Inhibitory Effect of L67 Protein on the Expression of GATA-3 and T-bet in BPA-Treated Primary Cultured Mouse Splenocytes}

As shown in Figure 3, expression of GATA-3 was increased by 2.6-fold in BPA-treated splenocytes, whereas expression of T-bet was reduced to 0.15 -fold compared with the control. The increased expression of GATA-3 was inhibited by L67 protein treatment in a dose-dependent manner, and the decreased expression of T-bet increased with L67 protein treatment. Expression of GATA-3 was reduced to 1.5-, 1.12-, 1.03-, and 0.6 - fold with $5,20,50$, and $100 \mu \mathrm{g} / \mathrm{mL}$ of $\mathrm{L} 67$ protein, respectively. Expression of T-bet was augmented to 0.2, 0.74-, 0.76-, and 0.8-fold at 5, 20, 50, and $100 \mu \mathrm{g} / \mathrm{mL}$ of L67 protein, respectively.

\section{Inhibitory Effect of L67 Protein on Gene Expression of IL-6, IL-10, and IL-1 $\beta$ in BPA-Treated RBL-2H3 Cells}

To study the effects of L67 protein treatment on allergy-related cytokines, we investigated the expression profile of IL-6, IL-10, and IL-1 $\beta$ genes in BPA-treated RBL-2H3 cells. As shown in Figure 4, cells stimulated with BPA showed significantly enhanced expression of IL- 6 , IL-10, and IL-1 $\beta$ compared the control. However, L67 protein treatment of cells led to inhibition of IL-6, IL-10, and IL-1 $\beta$ induction in a dose-dependent manner compared with BPA treatment alone. BPAinduced IL- 6 gene transcription increased by 4.5 -fold, but it decreased to 4.2-, 3.6-, 2.8-, 1.9-, and 1.8-fold upon addition of $5,20,50$, and $100 \mu \mathrm{g} / \mathrm{mL}$ of $\mathrm{L} 67$ protein, respectively. Similarly, IL-10 and IL-1 $\beta$ gene 
transcription both increased by 1.8 -fold in response to BPA treatment but decreased with the addition of L67 protein.

\section{Applicability of L. plantarum L67 as a Yogurt Starter Culture}

Table 5 shows the decremental change in $\mathrm{pH}$ during fermentation of cultures until $\mathrm{pH} 4.5$ (endpoint). Five hours of fermentation was required to reach a $\mathrm{pH}$ of 4.5 in all starter cultures. Probiotic strains L. acidophilus La5, L. acidophilus NCFM, Bifidobacterium animalis Bb12, and L. plantarum L67 did not have obvious differences in acidification.

The number of viable cells of $S$. thermophilus increased rapidly during fermentation, whereas bifidobacteria and lactobacilli increased steadily by approximately 1 $\log$ (Table 6). We observed no differences in fermentation time or total number viable of cells in the starter cultures. As shown in Table 7, organoleptic evaluation indicated that the yogurts with L. plantarum L67 showed results that were strikingly similar to the other commercial starters.

\section{DISCUSSION}

In the present study, we explored whether L67 protein inhibits the activity of allergy-related mediators, as well as the induction of cytokines in BPA-treated RBL-2H3 cells and in primary cultured splenocytes. Several studies have demonstrated that lactobacilli regulate macrophage activation and modulate the Th1/Th2 balance (Segawa et al., 2008; Won et al., 2011). Several strains of lactobacilli possess Th1-inducing activity, reduce total or ovalbumin-specific IgE production, and change associated cytokine patterns in a strain-dependent manner (Lee et al., 2013). First, we examined 18 strains of lactobacilli for their ability to induce secretion of Th1-related cytokines, such as IL-12 and IFN- $\gamma$, from mouse splenocytes. We selected L. plantarum L67 for further evaluation, based on its ability to induce high levels of IL-12 and IFN- $\gamma$ secretion (Table 1).

(A)

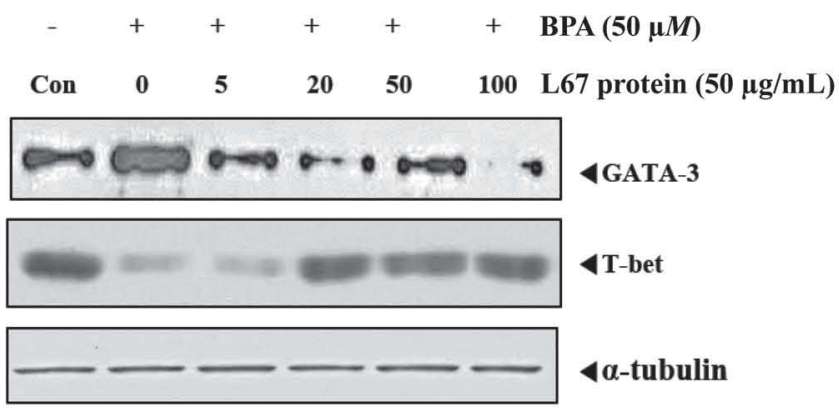

(B)

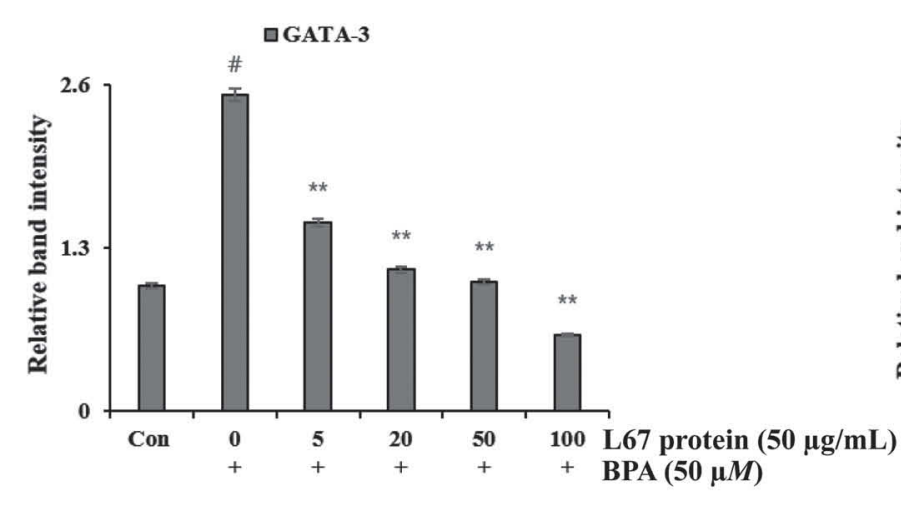

(C)

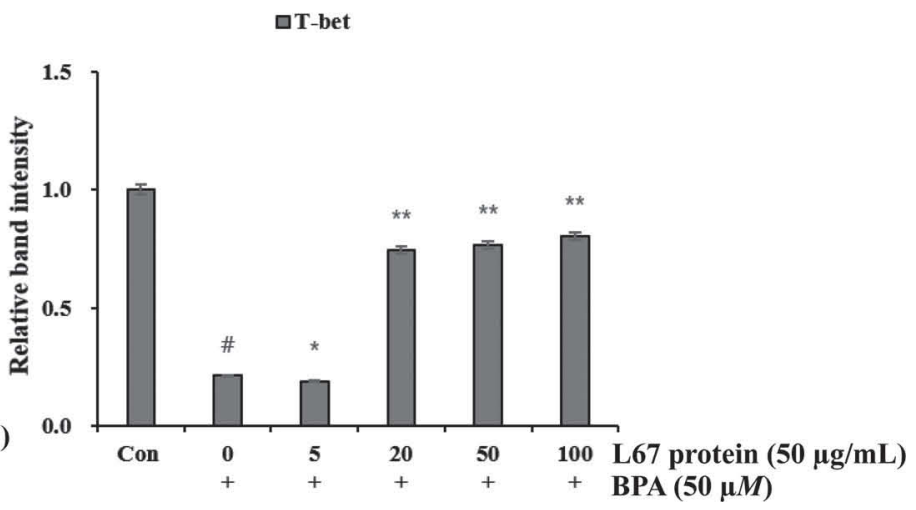

Figure 3. Inhibitory effect of Lactobacillus plantarum L67 protein on GATA-binding protein 3 and T-bet expression in bisphenol A (BPA)treated, primary cultured mouse splenocytes (Western blot in panel A; relative band intensities of GATA-3 and T-bet in panels B and C). Primary cultured mouse splenocytes were treated with BPA $(50 \mu M)$ for $30 \mathrm{~min}$ in the absence or presence of L67 protein $(5,20,50$, and 100 $\mu \mathrm{g} / \mathrm{mL}$ ). The relative intensities of the bands were analyzed using Scion imaging software (Scion Image Beta 4.02; Frederick, MD). $\alpha$-Tubulin was used as an internal control. All data are mean $\pm \mathrm{SE}$ from triplicates. \#Significant difference between treatments and controls $(P<0.05)$; ${ }^{*}, * *$ significant difference between BPA and L67 protein treatments in the presence of BPA $(* P<0.05 ; * * P<0.01)$. Con $=$ control. 
The mechanisms leading to a predominant Th2 response during T-cell differentiation are still not fully understood. Among the many factors associated with Th2 differentiation, MAPK is a key mediator of the expression of Th2-related cytokines such as IL-4 and IL-10 (Yamashita et al., 2005; Watanabe et al., 2005). Therefore, the MAPK signaling pathway is an important therapeutic target in allergic disorders induced by a predominantly Th2 immune response (Abdel-Raheem et al., 2005). We measured the activity of ERK and p38 to determine whether L67 protein suppressed MAPK signaling and, consequently, the expression of IL-1 $\beta$, IL-6, and IL-10. Our results showed that L67 protein inhibited BPA-induced ERK and p38 MAPK phosphorylation in RBL-2H3 cells. Further, it has been reported that various probiotics can inhibit inflammatory markers such as MAPK and AP-1 induced by lipopolysaccharides or other inflammatory derivatives (Kumar et al., 2014; Li et al., 2014; Jeong et al., 2015). In our study, L67 protein inhibited inflammatory response markers induced by BPA.

Activation of ERK or JNK leads to nuclear translocation of AP-1 and increased expression of pro-inflammatory cytokine genes (Banerjee and Gerondakis, 2007). Lactobacillus reuteri suppresses activation of the AP-1 translocation factor, which regulates the expression of pro-inflammatory cytokine genes in response to activation of toll-like receptor (Lin et al., 2008). In our study, L67 protein also inhibited activation of AP-1 (c-Fos and c-Jun).

Several factors are involved in cell development from Th0 to Th1 and Th2 cells. In particular, GATA-3 is well known as a key transcriptional factor in Th2 cell differentiation (Lin et al., 2008). Furthermore, activation of GATA-3 induces the production of Th2 cytokines such as IL-4 and IL-10 and represses the production of Th1-related cytokines. Patients with specific allergies also have increased expression of GATA-3 (Nakamura et al., 2000; Zhu et al., 2006). In this study, GATA-3 was upregulated by BPA, and expression of T-bet was reduced. The increased expression of GATA-3 induced by BPA treatment was suppressed by cotreatment with L67 protein; conversely, L67 protein treatment induced the expression of T-bet in BPA-treated splenocytes.

Table 5. Changes in $\mathrm{pH}$ values during yogurt fermentation with 3 different starter cultures (mean $\pm \mathrm{SE}$ )

\begin{tabular}{lcrr}
\hline Time & Starter A & Starter B & Starter C \\
\hline $0 \mathrm{~h}$ & $6.55 \pm 0.005$ & $6.52 \pm 0.004$ & $6.61 \pm 0.007$ \\
$2 \mathrm{~h}$ & $6.01 \pm 0.006$ & $5.98 \pm 0.006$ & $6.08 \pm 0.006$ \\
$4 \mathrm{~h}$ & $4.75 \pm 0.004$ & $4.68 \pm 0.006$ & $4.72 \pm 0.005$ \\
Endpoint & $4.44 \pm 0.007$ & $4.46 \pm 0.007$ & $4.45 \pm 0.005$ \\
& $(5 \mathrm{~h} 10 \mathrm{~min})$ & $(5 \mathrm{~h} 5 \mathrm{~min})$ & $(5 \mathrm{~h} 10 \mathrm{~min})$ \\
\hline
\end{tabular}

These results indicate that L67 protein helps to maintain the balance between Th1 and Th2 cells by regulating the expression of T-bet and GATA-3. Differentiated Th1 cells produce IFN- $\gamma$ and lymphotoxin, which are

IL-1B

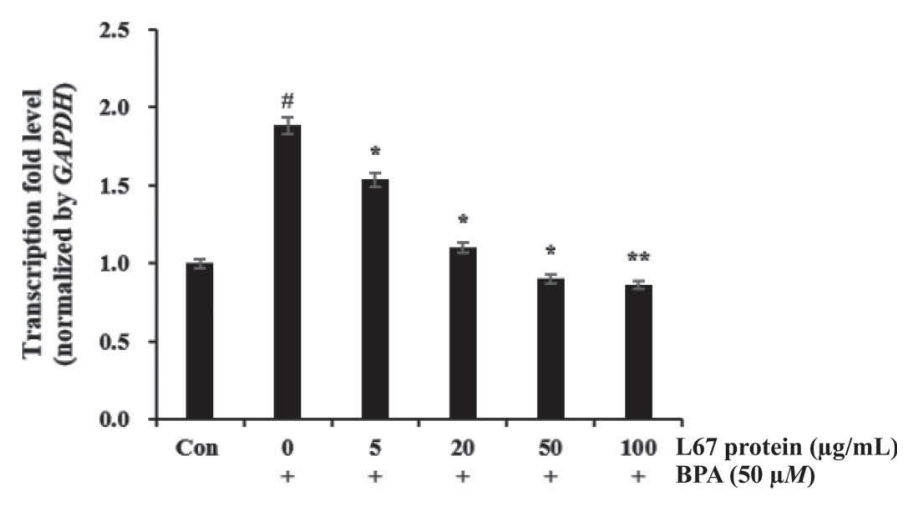

IL-10
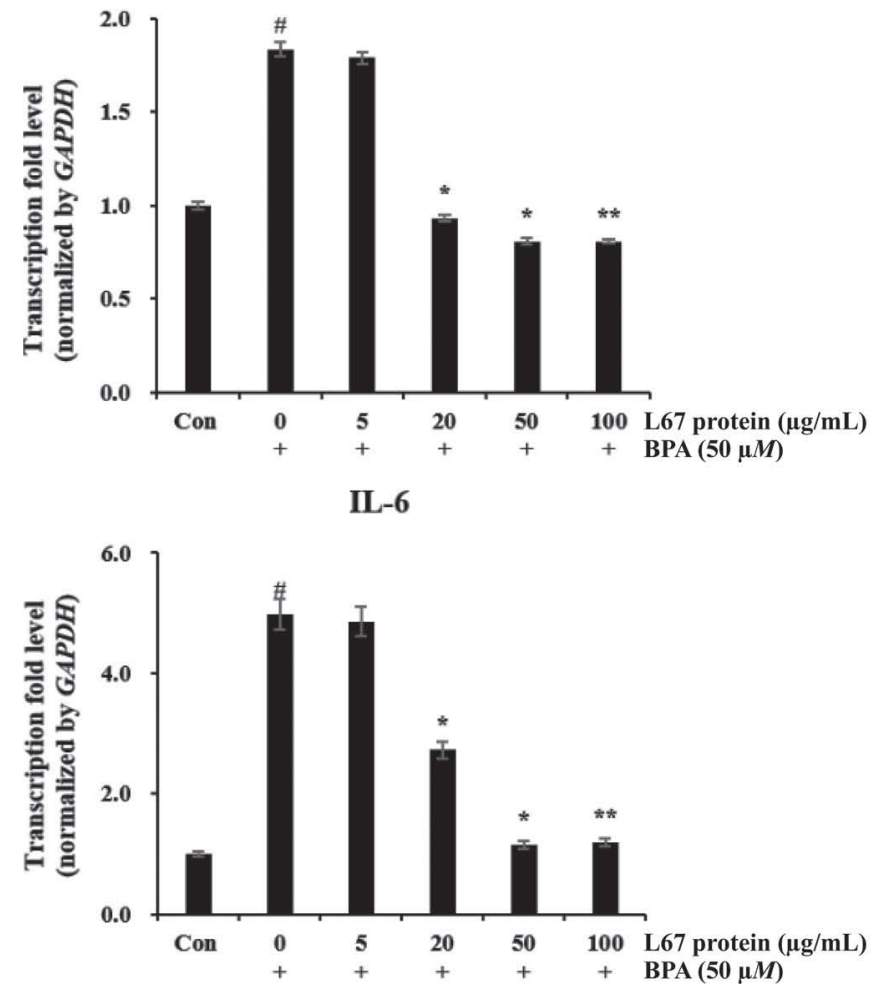

Figure 4. Inhibitory effect of Lactobacillus plantarum L67 protein on IL-1 $\beta$, IL-6, and IL-10 expression in bisphenol A (BPA)-treated RBL2H3 cells. Cells were treated with BPA $(50 \mu M)$ for 30 min in the absence or presence of L. plantarum L67 protein $(5,20,50$, and 100 $\mu \mathrm{g} / \mathrm{mL})$. The expression of IL-1 $\beta$, IL-6, and IL-10 mRNA was evaluated by real-time quantitative $\mathrm{PCR}$ using isolated total RNA. The mRNA levels (transcript fold level normalized to that of GAPDH) were calculated relative to the transcript levels detected in the untreated control. All data are mean \pm SD from triplicates. \#Significant difference between treatments and controls $(P<0.05)$; ${ }^{*} * *$ significant difference between BPA and L67 protein treatments in the presence of $\mathrm{BPA}\left({ }^{*} P<0.05 ; * * P<0.01\right)$. 
Table 6. Number of viable cells $(\mathrm{cfu} / \mathrm{mL})$ of lactic acid bacteria during yogurt fermentation with 3 different starter cultures

\begin{tabular}{lcc}
\hline Item & Initial & Final \\
\hline Starter A & $1.43 \times 10^{6} \pm 0.83$ & $1.21 \times 10^{7} \pm 1.12$ \\
Lactobacillus acidophilus La5 & $1.35 \times 10^{6} \pm 0.71$ & $9.10 \times 10^{7} \pm 2.15$ \\
Bifidobacterium animalis ssp. lactis Bb12 & $2.37 \times 10^{7} \pm 0.79$ & $1.63 \times 10^{9} \pm 0.62$ \\
$\quad$ Streptococcus thermophilus & $2.54 \times 10^{6} \pm 1.56$ & $1.01 \times 10^{7} \pm 0.61$ \\
Starter B & $1.83 \times 10^{6} \pm 0.81$ & $1.31 \times 10^{7} \pm 0.78$ \\
Lactobacillus acidophilus NCFM & $1.66 \times 10^{7} \pm 0.44$ & $1.93 \times 10^{9} \pm 1.14$ \\
Bifidobacterium longum & $1.02 \times 10^{6} \pm 1.27$ & $2.17 \times 10^{7} \pm 0.99$ \\
Streptococcus thermophilus & $1.12 \times 10^{6} \pm 0.44$ & $2.01 \times 10^{7} \pm 1.04$ \\
Starter C & $1.53 \times 10^{6} \pm 0.62$ & $1.88 \times 10^{9} \pm 0.95$ \\
$\quad$ Lactobacillus plantarum L67 & & \\
Bifidobacterium longum & &
\end{tabular}

necessary for immune resistance against intracellular pathogens (Glimcher and Murphy, 2000). In contrast, Th2 cells release IL-1 $\beta$, IL-6, and IL-10, which are associated with atopic and allergic reactions (Tillie-Leblond et al., 1999; Herrick et al., 2000). We know that IL-1 $\beta$ is a key stimulator in the class switching process that replaces IgE to regulate Th2 and B cells, and that IL10 functions as a vital inhibitor of IL-12 and IFN- $\gamma$ (Th1 cytokines), which inhibit the differentiation of Th1 cells (Ritter et al., 2014; Murphy et al., 2000). Because BPA induces the Th2 response, we examined gene expression of IL-1 $\beta$, IL-6, and IL-10 in RBL-2H3 cells and found that treatment with BPA stimulated the expression of IL-1 $\beta$, IL-6, and IL-10. This indicated that BPA promotes the differentiation of Th0 cells to Th2 cells via IL-1 $\beta$, IL-6, and IL- 10 . However, the increased expression of IL-1 $\beta$, IL- 6 , and IL-10 induced by BPA treatment was significantly inhibited by L 67 protein treatment.

We also evaluated the applicability of $L$. plantarum L67 as a yogurt starter culture. L. planetarium L67 did not have obvious effects on acidification. We also observed no differences in fermentation time or total number of viable cells in the starter cultures. The organoleptic evaluation indicated that the yogurts with $L$. plantarum L67 showed strikingly similar results to the other commercial starters. During milk fermentation,

Table 7. Mean values for sensory evaluation ${ }^{1}$ of yogurt with 3 different starter cultures (mean $\pm \mathrm{SE}$ )

\begin{tabular}{lccc}
\hline Starter & $\begin{array}{c}\text { Flavor } \\
\text { score }\end{array}$ & $\begin{array}{c}\text { Texture } \\
\text { score }\end{array}$ & $\begin{array}{c}\text { Preference } \\
\text { score }\end{array}$ \\
\hline $\mathrm{A}$ & $7.12 \pm 0.051$ & $3.21 \pm 0.048$ & $3.43 \pm 0.053$ \\
$\mathrm{~B}$ & $7.45 \pm 0.053$ & $3.19 \pm 0.042$ & $3.51 \pm 0.056$ \\
$\mathrm{C}$ & $7.36 \pm 0.049$ & $3.25 \pm 0.051$ & $3.57 \pm 0.061$ \\
\hline
\end{tabular}

${ }^{1}$ Sensory rating scales: flavor: $1-9$ points, no criticism $=9$; texture: $1-5$ points; no criticism $=5$; and preference: $1-5$ points; no criticism $=5$. None of the differences among starters were significant. lactic acid bacteria can convert lactose into lactic acid, which contributes to the yogurt's taste and texture (Tamime and Deeth, 1980). Hekmat and Reid (2006) reported that the addition of probiotics does not significantly alter the sensory properties of yogurt, because most probiotic strains are not major milk-fermenting microorganisms (Cruz et al., 2010). On the other hand, $S$. thermophilus and L. delbrueckii ssp. bulgaricus are reported to be exclusively responsible for the production of flavor compounds such as acetaldehyde, diacetly, and acetoin (Cheng, 2010). These results suggest that $L$. plantarum L67 is capable of being used in mixed-strain cultures in yogurt manufacturing.

The current study shows that L67 protein inhibits the phosphorylation of ERK and p38 MAPK, as well as the activation of AP-1 (c-Fos and c-Jun). With inflammation-related factors (Th2-related cytokines), L67 protein inhibits BPA-induced IL-1 $\beta$, IL-6, and IL-10 activity. Bisphenol A stimulates MAPK signaling, which induces increased GATA-3 expression, and GATA-3 induces the differentiation of Th2 cells and secretion of Th2-related cytokines. Our findings showed that L67 protein may regulate the activation of GATA3 and T-bet through the induction of MAPK signaling, and it relieves the Th1/Th2 cytokine profile imbalance. Taken together, these findings demonstrate that the $L$. plantarum L67 strain is a potential food supplement and starter culture, that could help in the prevention of Th2-related immune disorders.

\section{ACKNOWLEDGMENTS}

This research was supported by Basic Science Research Program through the National Research Foundation of Korea (NRF) funded by the Ministry of Science, ICT \& Future Planning (NRF-2016R1A2B4007519). This study was also supported by Chonnam National University, Gwang-Ju, South Korea. The authors declare no conflicts of interest. 


\section{REFERENCES}

Abdel-Raheem, I. T., I. Hide, Y. Yanase, Y. Shigemoto-Mogami, N. Sakai, Y. Shirai, N. Saito, F. M. Hamada, N. A. El-Mahdy, Ael-D. Elsisy, S. S. Sokar, and Y. Nakata. 2005. Protein kinase C-alpha mediates TNF release process in RBL-2H3 mast cells. Br. J. Pharmacol. 145:415-423.

Andersson, U., C. Bränning, S. Ahrné, G. Molin, J. Alenfall, G. Onning, M. Nyman, and C. Holm. 2010. Probiotics lower plasma glucose in the high-fat fed C57BL/6J mouse. Benef. Microbes $1: 189-196$

Banerjee, A., and S. Gerondakis. 2007. Coordinating TLR-activated signaling pathways in cells of the immune system. Immunol. Cell Biol. 85:420-424.

Bornehag, C. G., J. Sundell, C. J. Weschler, T. Sigsgaard, B. Lundgren, M. Hasselgren, and L. Hagerhed-Engman. 2004. The association between asthma and allergic symptoms in children and phthalates in house dust: A nested case control study. Environ. Health Perspect. 112:1393-1397.

Bradford, M. M. 1976. A rapid and sensitive method for the quantitation of microgram quantities of protein utilizing the principle of protein-dye binding. Anal. Biochem. 72:248-254.

Chalubinski, M., and M. L. Kowalski. 2006. Endocrine disrupterspotential modulators of the immune system and allergic response. Allergy 61:1326-1335.

Cheng, H. 2010. Volatile flavor compounds in yogurt: A review. Crit. Rev. Food Sci. Nutr. 50:938-950.

Cruz, A. G., J. A. F. Faria, E. H. M. Walter, R. R. Andrade, R. N. Cavalcanti, C. A. F. Oliveira, and D. Granato. 2010. Processing optimization of probiotic yogurt containing glucose oxidase using response surface methodology. J. Dairy Sci. 93:5059-5068.

Dave, R. I., and N. P. Shah. 1996. Evaluation of media for selective enumeration of Streptococcus thermophilus, Lactobacillus delbrueckii ssp. bulgaricus, Lactobacillus acidophilus, and bifidobacteria. J. Dairy Sci. 79:1529-1536.

Giardina, S., C. Scilironi, A. Michelotti, A. Samuele, F. Borella, M. Daglia, and F. Marzatico. 2014. In vitro anti-inflammatory activity of selected oxalate-degrading probiotic bacteria: Potential applications in the prevention and treatment of hyperoxaluria. J. Food Sci. 79:M384-390.

Glimcher, L. H., and K. M. Murphy. 2000. Lineage commitment in the immune system: The T helper lymphocyte grows up. Genes Dev. 14:1693-1711.

Hekmat, S., and G. Reid. 2006. Sensory properties of probiotic yogurt is comparable to standard yogurt. Nutr. Res. 26:163-166.

Herrick, C. A., H. MacLeod, E. Glusac, R. E. Tigelaar, and K. Bottomly. 2000. Th2 responses induced by epicutaneous or inhalational protein exposure are differentially dependent on IL-4. J. Clin. Invest. 105:765-775.

Hong, Y. F., H. Kim, H. R. Kim, M. G. Gim, and D. K. Chung. 2014. Different immune regulatory potential of Lactobacillus plantarum and Lactobacillus sakei isolated from kimchi. J. Microbiol. Biotechnol. 24:1629-1635.

Jaakkola, J. J., H. Parise, V. Kislitsin, N. I. Lebedeva, and J. D. Spengler. 2004. Asthma, wheezing, and allergies in Russian schoolchildren in relation to new surface materials in the home. Am. J. Public Health 94:560-562.

Jeong, J. J., K. A. Kim, S. E. Jang, J. Y. Woo, M. J. Han, and D. H. Kim. 2015. Orally administrated Lactobacillus pentosus var. plantarum C29 ameliorates age-dependent colitis by inhibiting the nuclear factor-kappa B signaling pathway via the regulation of lipopolysaccharide production by gut microbiota. PLoS One 10:e0116533.

Johnson-Henry, K. C., K. E. Hagen, M. Gordonpour, T. A. Tompkins, and P. M. Sherman. 2007. Surface-layer protein extracts from Lactobacillus helveticus inhibit enterohaemorrhagic Escherichia coli 0157:H7 adhesion to epithelial cells. Cell. Microbiol. 9:356-367.

Kassayová, M., N. Bobrov, L. Strojný, T. Kisková, J. Mikeš, V. Demečková, P. Orendáš, B. Bojková, M. Péč, P. Kubatka, and A. Bomba. 2014. Preventive effects of probiotic bacteria Lactobacil- lus plantarum and dietary fiber in chemically-induced mammary carcinogenesis. Anticancer Res. 34:4969-4975.

Konieczna, P., E. Schiavi, M. Ziegler, D. Groeger, S. Healy, R. Grant, and L. O'Mahony. 2015. Human dendritic cell DC-SIGN and TLR-2 mediate complementary immune regulatory activities in response to Lactobacillus rhamnosus JB-1. PLoS One 10:e0120261.

Konstantinov, S. R., H. Smidt, W. M. de Vos, S. C. Bruijns, S. K. Singh, F. Valence, D. Molle, S. Lortal, E. Altermann, T. R. Klaenhammer, and Y. van Kooyk. 2008. S layer protein A of Lactobacillus acidophilus NCFM regulates immature dendritic cell and T cell functions. Proc. Natl. Acad. Sci. USA 105:19474-19479.

Kumar, A., C. Hecht, S. Priyamvada, A. N. Anbazhagan, A. Alakkam, A. Borthakur, W. A. Alrefai, R. K. Gill, and P. K. Dudeja. 2014 Probiotic Bifidobacterium species stimulate human SLC26A3 gene function and expression in intestinal epithelial cells. Am. J. Physiol. Cell Physiol. 307:C1084-C1092.

Lee, J., J. Bang, and H. J. Woo. 2013. Immunomodulatory and antiallergic effect of orally administered Lactobacillus species in ovalbumin-sensitized mice. J. Microbiol. Biotechnol. 23:724-730.

Lee, J., and K. T. Lim. 2010. Plant-originated glycoprotein (36 kDa) suppresses interleukin- 4 and -10 in bisphenol A-stimulated primary cultured mouse lymphocytes. Drug Chem. Toxicol. 33:421-429.

Li, L., Y. J. Jiang, X. Y. Yang, Y. Liu, J. Y. Wang, and C. X. Man. 2014. Immunoregulatory effects on Caco-2 cells and mice of exopolysaccharides isolated from Lactobacillus acidophilus NCFM. Food Funct. 5:3261-3268.

Li, S., Y. Zhao, L. Zhang, X. Zhang, L. Huang, D. Li, C. Niu, Z. Yang, and Q. Wang. 2012. Antioxidant activity of Lactobacillus plantarum strains isolated from traditional Chinese fermented foods. Food Chem. 135:1914-1919.

Lin, Y. P., C. H. Thibodeaux, J. A. Pena, G. D. Ferry, and J. Versalovic. 2008. Probiotic Lactobacillus reuteri suppress proinflammatory cytokines via c-Jun. Inflamm. Bowel Dis. 14:1068-1083.

Livak, K. J., and T. D. Schmittgen. 2001. Analysis of relative gene expression data using real-time quantitative PCR and the $2^{-\triangle \Delta \mathrm{CT}}$ method. Methods 25:402-408.

Lowry, O. H., N. J. Rosebrough, A. L. Farr, and R. J. Randall. 1951. Protein measurement with the Folin phenol reagent. J. Biol. Chem. 193:265-275.

Murphy, K. M., W. Ouyang, J. D. Farrar, J. Yang, S. Ranganath, H. Asnagli, M. Afkarian, and T. L. Murphy. 2000. Signaling and transcription in $\mathrm{T}$ helper development. Annu. Rev. Immunol. 18:451-494.

Nakamura, Y., P. Christodoulopoulos, L. Cameron, E. Wright, F. Lavigne, M. Toda, S. Muro, A. Ray, D. H. Eidelman, E. Minshall, and Q. Hamid. 2000. Upregulation of the transcription factor GATA-3 in upper airway mucosa after in vivo and in vitro allergen challenge. J. Allergy Clin. Immunol. 105:1146-1152.

O'Brien, E., D. C. Dolinoy, and P. Mancuso. 2014. Perinatal bisphenol A exposures increase production of pro-inflammatory mediators in bone marrow-derived mast cells of adult mice. J. Immunotoxicol. $11: 205-212$.

Oh, P. S., and K. T. Lim. 2008. Protective activity of $30 \mathrm{kDa}$ phytoglycoprotein from glucose/glucose oxidase-induced cell death in primary cultured mouse thymocytes. Environ. Toxicol. Pharmacol. 25:114-120.

Park, Y. S., J. Y. Lee, Y. S. Kim, and D. H. Shin. 2002. Isolation and characterization of lactic acid bacteria from feces of newborn baby and from Dongchimi. J. Agric. Food Chem. 50:2531-2536.

Rhee, C. H., and H. D. Park. 2001. Three glycoproteins with antimutagenic activity identified in Lactobacillus plantarum KLAB21. Appl. Environ. Microbiol. 67:3445-3449.

Ritter, M., K. Straubinger, S. Schmidt, D. H. Busch, S. Hagner, H. Garn, C. Prazeres da Costa, and L. E. Layland. 2014. Functional relevance of NLRP3 inflammasome-mediated interleukin (IL)-1 $\beta$ during acute allergic airway inflammation. Clin. Exp. Immunol. 178:212-223.

Segawa, S., Y. Nakakita, Y. Takata, Y. Wakita, T. Kaneko, H. Kaneda, J. Watari, and H. Yasui. 2008. Effect of oral administration of heat-killed Lactobacillus brevis SBC8803 on total and ovalbumin- 
specific immunoglobulin E production through the improvement of Th1/Th2 balance. Int. J. Food Microbiol. 121:1-10.

Song, M., B. Yun, J.-H. Moon, D.-J. Park, K. Lim, and S. Oh. 2015. Characterization of selected Lactobacillus strains for use as probiotics. Korean J. Food Sci. Anim. 35:551-556.

Song, S., D. W. Bae, K. Lim, M. W. Griffiths, and S. Oh. 2014. Cold stress improves the ability of Lactobacillus plantarum L67 to survive freezing. Int. J. Food Microbiol. 191:135-143.

Song, S., S. Oh, and K. T. Lim. 2016a. Glycoprotein (18 kDa) isolated from Lactobacillus plantarum L67 suppressed $\beta$-hexosaminidase, histamine, and the expression of TNF- $\alpha$ and IL-4 in the BPAstimulated RBL-2H3 cells. Process Biochem. 51:105-112.

Song, S., S. Oh, and K. T. Lim. 2016b. Lactobacillus plantarum L67 glycoprotein protects against cadmium chloride toxicity in RAW 264.7 cells. J. Dairy Sci. 99:1812-1821.

Sornplang, P., and S. Piyadeatsoontorn. 2016. Probiotic isolates from unconventional sources: A review. J. Anim. Sci. Technol. 58:26.

Szabo, S. J., S. T. Kim, G. L. Costa, X. Zhang, C. G. Fathman, and L. H. Glimcher. 2000. A novel transcription factor, T-bet, directs Th1 lineage commitment. Cell 100:655-669.

Szabo, S. J., B. M. Sullivan, S. L. Peng, and L. H. Glimcher. 2003 Molecular mechanisms regulating Th1 immune responses. Annu. Rev. Immunol. 21:713-758.

Tamime, A. Y., and H. C. Deeth. 1980. Yogurt: Technology and biochemistry. J. Food Prot. 12:939-977.

Teraguchi, S., M. Uehara, K. Ogasa, and T. Mitsuoka. 1978. Enumeration of bifidobacteria in dairy products. Nippon Saikingaku Zasshi 33:753-761.

Tillie-Leblond, I., J. Pugin, C. H. Marquette, C. Lamblin, F. Saulnier, A. Brichet, B. Wallaert, A. B. Tonnel, and P. Gosset. 1999. Bal- ance between proinflammatory cytokines and their inhibitors in bronchial lavage from patients with status asthmaticus. Am. J. Respir. Crit. Care Med. 159:487-494.

Vandenberg, L. N., R. Hauser, M. Marcus, N. Olea, and W. Welshons. 2007. Human exposure to bisphenol A (BPA). Reprod. Toxicol. $24: 139-177$

Watanabe, M., S. Watanabe, Y. Hara, Y. Harada, M. Kubo, K. Tanabe, H. Toma, and R. Abe. 2005. ICOS-mediated costimulation on Th2 differentiation is achieved by the enhancement of IL-4 receptor-mediated signaling. J. Immun. 174:1989-1996.

Won, T. J., B. Kim, D. S. Song, Y. T. Lim, E. S. Oh, D. I. Lee, E. S. Park, H. Min, S. Y. Park, and K. W. Hwang. 2011. Modulation of Th1/Th2 balance by Lactobacillus strains isolated from Kimchi via stimulation of macrophage cell line J774A.1 in vitro. J. Food Sci. 76:H55-61.

Yamashita, M., R. Shinnakasu, H. Asou, M. Kimura, A. Hasegawa, K. Hashimoto, N. Hatano, M. Ogata, and T. Nakayama. 2005. Ras-ERK MAPK cascade regulates GATA3 stability and Th2 differentiation through ubiquitin proteasome pathway. J. Biol. Chem. 280:29409-29419.

Yan, H., M. Takamoto, and K. Sugane. 2008. Exposure to bisphenol A prenatally or in adulthood promotes $\mathrm{T}(\mathrm{H}) 2$ cytokine production associated with reduction of CD4CD25 regulatory T cells. Environ. Health Perspect. 116:514-519.

Zhu, J., H. Yamane, J. Cote-Sierra, L. Guo, and W. E. Paul. 2006. GATA-3 promotes Th2 responses through three different mechanisms: Induction of Th2 cytokine production, selective growth of Th2 cells and inhibition of Th1 cell-specific factors. Cell Res. $16: 3-10$ 